\title{
A docência no armário: 0 silenciamento das relações de gênero nos planos de educação
}

\author{
Teaching in the closet: the silencing of gender relations in education plans
}

Ivan Amaro*

\section{Resumo}

No Brasil, a redemocratização trouxe esperança para a construção de um país ancorado em princípios de respeito, participação, liberdade de expressão, diferença, diversidade. Paradoxalmente, o enfrentamento dos preconceitos, da violência, da discriminação permanece, ainda, como pauta prioritária de uma agenda democrática e defensora dos direitos humanos, tendo em vista uma perspectiva conservadora que se expressa em organizações religiosas e embrenham-se nas estruturas políticas de decisão do Estado. O objetivo é problematizar os desdobramentos a partir da aprovação do Plano Nacional de Educação (PNE 2014-2024), identificando de que forma as temáticas de gênero e sexualidade foram demarcadas na elaboração dos Planos Municipais de Educação (PMEs). O foco deste estudo recai sobre algumas reflexões acerca das (in)conformações que se materializam nos PMEs de dois municípios da Baixada Fluminense, situando-as no contexto de movimentos conservadores locais e de perspectivas de intervirem no trabalho docente, estabelecendo um contexto de proibições e silenciamentos. Ao mesmo tempo em que o alinhamento dos planos estaduais e municipais ao PNE pode manter a "docência no armário" e "amordaçar" docentes, há, também, brechas para implementar ações de combate ao preconceito, à discriminação, à violência em relação às diversas manifestações de gênero e de orientação sexual.

Palavras-chave: Gênero. Planos de educação. Sexualidade.

\section{Abstract}

In Brazil, democratization has brought hope to build a country anchored in principles of respect, participation, freedom of expression, difference, diversity. Paradoxically, the face of prejudice, violence, discrimination still remains a priority agenda of a democratic agenda and defender of human rights with a view to a conservative perspective that is expressed in religious organizations and it penetrates on the decision of political structures State. The intention is to discuss the developments since the adoption of the National Education Plan (PNE 2014-2024), identifying how the themes of gender and sexuality were demarcated in the preparation of Municipal Education Plans (SMEs). The focus of this study lies with some reflections on the (in)conformations that materialize in SMEs in two municipalities of the Baixada Fluminense, placing them in the context of local conservative movements and prospects to intervene in teaching, setting a context of prohibitions and silences. While the alignment of state municipal plans and to PNE can keep the "teaching in the closet" and "gag" teachers, there are also gaps in their efforts to combat prejudice, discrimination, violence towards various gender expressions and sexual orientation.

Keywords: Gender. Education Plans. Sexuality.

Recebido em: 15/05/2016 - Aprovado em: 19/10/2016

http://dx.doi.org/10.5335/rep.v24i1.6998

Doutor em Educação pela Universidade Estadual de Campinas. Professor do Departamento de Formação de Professores e do Programa de Pós-Graduação em Educação, Cultura e Comunicação em Periferias Urbanas da Universidade do Estado do Rio de Janeiro. E-mail: ivanamaro.uerj@gmail.com 


\section{Gênero: uma concepção em disputa nos planos de educação}

A Constituição federal brasileira de 1988, em seu art. 214, indicou a elaboração e implantação do Plano Nacional de Educação (PNE) como política de estado. A Emenda Constitucional no 59/2009 estabeleceu sua duração decenal e aperfeiçoou sua finalidade, que prevê a articulação do sistema educacional em regime colaborativo entre os entes federados, definindo "diretrizes, objetivos, metas e estratégias de implementação para assegurar a manutenção e desenvolvimento do ensino, em seus diversos níveis, etapas e modalidades, por meio de ações integradas das diferentes esferas federativas" (BRASIL, 2009, p. 9).

A presidência da República, em dezembro de 2010, por meio da Mensagem 701, acompanhada da Exposição de Motivos no 33/2010, encaminhou projeto de lei que aprovaria o Plano Nacional de Educação para o decênio 2011-2020 e daria outras providências. ${ }^{1}$ No entanto, sua tramitação ocorreu ao longo de três anos e seis meses no Congresso Nacional, sendo sancionada a Lei no 13.005, em 25 de junho de 2014. Esse atraso se deve, além dos processos complexos de ajustes de calendário para realização de audiências públicas, debates, seminários, principalmente, pelo cenário de tensões e disputas que envolveram seu percurso no Congresso Nacional.

Vale ressaltar que a proposição ocorreu a partir da mobilização e participação de todos os entes federados nas conferências preparatórias e livres municipais e/ ou intermunicipais, estaduais e do Distrito Federal, realizadas ao longo de 2013, para discutir o Documento Referência, aprovado pelo Fórum Nacional de Educação, criado pela Portaria n⿳o 1.407/2010 e alterado pela Portaria no 502/2012, órgão responsável por convocar e realizar a II Conferência Nacional de Educação ${ }^{2}$ (Conae 2014). Segundo o Documento Referência Final da II Conae (BRASIL, 2014), foram inseridas cerca de 30.000 emendas ao texto e as conferências (municipais e/ou intermunicipais, estaduais e distrital) mobilizaram, aproximadamente, 3,6 milhões de pessoas, um número bastante significativo.

Diversas audiências públicas foram realizadas pela Comissão de Educação da Câmara dos Deputados e do Senado Federal em seu processo de tramitação. Nesse contexto, parecia haver razoável consenso em relação à grande parte das metas e das estratégias. Entretanto, alguns pontos tornaram-se focos de polêmica acirrada entre os diversos setores no Congresso.

O financiamento da educação foi um deles. Incluía dois elementos relevantes: a definição do percentual de 10\% do Produto Interno Bruto (PIB) para investimento em educação e a implantação do Custo-Qualidade-Aluno inicial (CAQi) e do Custo-Aluno-Qualidade (CAQ). 
Outro foco de polêmica situou-se sobre a Meta 4 (Educação Especial). Todavia, a polêmica mais barulhenta recaiu sobre a diretriz que previa a superação das desigualdades educacionais. No inciso III do art. $2^{\circ}$ do substitutivo da Câmara, a ênfase recaía na "promoção da igualdade racial, regional, de gênero e de orientação sexual". Essa foi a oportunidade para que setores religiosos fundamentalistas, católicos e conservadores orquestrassem verdadeira "sinfonia de impropriedades". Uma delas foi a massificação da expressão equivocada "ideologia de gênero".

Tais setores, ancorados em um discurso de defesa da "família", de "valores morais" embasados na "lei natural", promoveram verdadeiro estardalhaço para a supressão dos termos gênero e orientação sexual da referida diretriz. Esse movimento emperrou o trâmite do $\mathrm{PNE}$, provocando mais um atraso em sua aprovação. É evidente que a disputa visou à intensificação do combate ao avanço das pautas reivindicadas, principalmente, pelo movimento de Lésbicas, Gays, Bissexuais, Travestis e Transexuais (LGBT), que incluíam o combate à violência, ao preconceito e à discriminação, o respeito à diversidade sexual, a criminalização da homofobia e a despatologização do segmento transexual. De outro modo, deixa bastante claro o posicionamento também relativo às lutas das mulheres contra o machismo, o sexismo, a violência e o feminicídio.

Nesse processo de intensa disputa, o Senado Federal alterou o texto para "superação das desigualdades educacionais, com ênfase na promoção da cidadania e na erradicação de todas as formas de discriminação" (BRASIL, 2014), de forma abrangente e vaga, o que permite interpretações diversas e abertas.

Em nível municipal, os movimentos religiosos, principalmente, representados nas Câmaras de Vereadores organizaram-se para obstaculizar a implementação de políticas públicas em defesa dos direitos de mulheres, dos direitos sexuais e reprodutivos, dos direitos de gays, lésbicas, bissexuais, travestis, transexuais e de quaisquer sujeitos que se distanciem das vertentes homogeneizadoras e heteronormativas afirmadas nos discursos conservadores.

No momento atual, o país passa por um conjunto de conflitos e retrocessos no cenário político e nas políticas públicas. Dentre os retrocessos, diversos estados e municípios têm aprovado leis que proíbem qualquer discussão sobre gênero e diversidade sexual nas escolas públicas. Um exemplo é a Lei $\mathrm{n}^{\circ} 4.576$, de 15 de fevereiro de 2016, do município de Nova Iguaçu, que veda a distribuição, exposição e divulgação de material didático contendo orientações sobre diversidade sexual nos estabelecimentos de ensino da rede pública do município, o que inclui a proibição de qualquer ação que vise ao combate da homofobia.

Além disso, há projetos e leis que procuram proibir professores e professoras de fazer qualquer menção a gênero ou sexualidade no desenvolvimento de seu tra- 
balho, estabelecendo uma verdadeira cultura da "mordaça" e de afronta ao direito constitucional da livre manifestação do pensamento bem como ao direito de liberdade de expressão da atividade intelectual e o exercício da profissão. Em abril de 2016, na Câmara Municipal de Campo Grande, MS, foi aprovado projeto de lei que veta temas como sexualidade, religião e política nas escolas municipais da cidade.

Tais iniciativas têm o claro objetivo de "amordaçar" professores e professoras no exercício de sua função. Trata-se de movimento conservador com vistas a repreender e coibir qualquer discussão sobre gênero e sexualidade na escola.

Neste artigo, buscamos problematizar os desdobramentos advindos da aprovação do PNE 2014-2024, identificando de que forma a diretriz que trata das desigualdades educacionais, principalmente, no trato dos preconceitos e discriminações correlatos às relações de gênero que foram demarcadas na elaboração dos planos estaduais e municipais de educação, e, especificamente, nossa atenção recai sobre o objetivo de provocar algumas reflexões acerca das (in)conformações que se materializam nos Planos Municipais de Educação (PMEs) de municípios da Baixada Fluminense, ${ }^{3}$ situando-as no contexto de movimentos conservadores locais. Pretende-se, ainda, identificar as estratégias que esses municípios têm apontado em seus planos para a "erradicação de todas as formas de discriminação", como registrado na diretriz III do PNE 2014-2014.

Compreendemos que, ao mesmo tempo em que o alinhamento dos planos estaduais e municipais ao PNE pode manter a "escola no armário"4 e "amordaçar professores e professoras" ${ }^{5}$ há também brechas para implementar ações de combate ao preconceito, à discriminação e à violência em relação às diversas manifestações de gênero e de orientação sexual. Compreender os pressupostos contraditórios dessas dinâmicas em diálogo com o movimento modernidade/colonialidade pode contribuir para vislumbrarmos seus pontos de contato com perspectiva de desconstruir estereótipos, estigmas, preconceitos e discriminações que cercam as relações de gênero e a diferença sexual, contribuindo para a ampliação da violência simbólica e física a que são submetidos os alunos das escolas públicas.

Para tanto, este artigo organiza-se em três partes. Na primeira, discutiremos os apagamentos e silenciamentos que as relações de gênero e sexualidade vêm sofrendo no espaço escolar, principalmente em relação ao trabalho docente, problematizando o cenário de opressão que se configura com a ausência de discussão sobre o assunto, bem como as interdições e proibições em curso nos planos de educação e em leis locais. Busca-se traçar um quadro das opressões sexuais que intersectam com outras formas de opressão, como etnia, raça e questões sociais. $\mathrm{Na}$ segunda parte, focalizamos nos desdobramentos do PNE 2014-2024 a partir do cenário que se configura na elaboração dos planos de educação no estado do Rio 
de Janeiro e, em seguida, nos dois planos municipais de educação, foco de nossas reflexões: o PME de Duque de Caxias e o PME de Nova Iguaçu. Por fim, apresentamos uma síntese propositiva que se inscreve no cerne dos direitos humanos e da legislação vigente, de modo a constituir movimentos de combate ao preconceito e à discriminação, tais como a violência contra a mulher, a homofobia, a bifobia, a lesbofobia e a transfobia.

\section{Gênero e sexualidade amordaçados na escola: entre interdições e silenciamentos}

A escola, em suas tessituras e como uma rede de acontecimentos, conflitos, dissensos e consensos, é um espaço-tempo de contradições, disputas e possibilidades diversas. Como parte de uma extensa rede intrincada e imbricada por complexos fios, em que acontecimentos, fazeres, pensares, reflexões são produzidos com intenções várias por seus sujeitos, o cotidiano escolar é um espaço-tempo de virtuosidades, embora seja também uma arena de disputas entremeadas por relações de poder.

Cotidianamente, percebem-se situações injuriosas, humilhantes, intimidantes, preconceituosas e discriminatórias que invadem o espaço escolar, conformando-o como lugar de estigmas, de controle e vigilância, classificações, hierarquizações (JUNQUEIRA, 2014). Para melhor compreender o que a escola tem produzido, a partir do silenciamento, do apagamento e da ocultação - ou de sua explicitação em práticas preconceituosas e discriminatórias - dos temas correlatos a gênero e às diversas orientações sexuais, é preciso perceber as motivações desses ocultamentos e das interdições pelas quais se submetem, principalmente, conhecimentos que envolvem os eixos relativos à sexualidade humana, às questões de gênero e aos preconceitos instalados e reforçados nas práticas pedagógicas no dia a dia de nossas salas de aulas.

Pesquisas mostram que a escola, por meio de seus processos pedagógicos, ao invés de desenvolver uma postura crítica, reflexiva e formativa, a partir de um enfoque de respeito às diferenças, à diversidade sexual e às relações de gênero, naturaliza posturas heteronormativas e misóginas, configuradas em brincadeiras, piadinhas, apelidos que desqualificam o outro que não se "comporta" ou não se adequa às normas ou aos padrões impostos. Tais ações constituem-se em uma pedagogia do insulto, em que manifestações preconceituosas, jocosas, ofensivas, discriminatórias e violentas tornam-se rotina na escola e explicitam, desde cedo, estratégias diversas de poder, de controle e de vigilância das corporalidades infantis e juvenis (JUNQUEIRA, 2012). Essa pedagogia do insulto configura os atos de meninos e meninas que são aprendidos para se dirigirem "àqueles e àquelas que 
não se ajustam aos padrões de gênero e de sexualidade admitidos na cultura em que vivem" (LOURO, 2014, p. 22).

Assim, humilhações, xingamentos, preconceitos, insultos por parte de outras crianças são tolerados e, até mesmo, reforçados à medida que não sofrem nenhuma intervenção educativa de educadores e educadoras, e acabam sendo disseminados na cultura escolar.

Segundo Miskolci (2012), a heteronormatividade é uma ordem política e social em que todos organizam suas vidas em conformidade como o padrão 'supostamente coerente' e pretensamente universal da heterossexualidade. Para o autor, "[...] a heteronormatividade é a ordem sexual do presente, fundada no modelo heterossexual, familiar e reprodutivo. Ela se impõe por meio de violências simbólicas e físicas dirigidas principalmente a quem rompe normas de gênero" (2012, p. 44).

Aqueles que não se filiam às regras de gênero e à matriz heterossexual são colocados à margem e tornam-se alvos de ridicularização e intimidação. Nesse sentido, o papel dos docentes é desconstruir tais padrões de homogeneização ao modelo heterossexual, compreendendo que há outras conformações da sexualidade. Além disso, a conduta docente parece inscrever-se na desconsideração das questões de gênero como potentes e possibilitadoras da formação de sujeitos e de enfrentamentos aos comportamentos discriminatórios que vão ganhando contornos de legitimidade e valorizadas no espaço escolar. Importante salientar que as diferenças entre meninos e meninas podem consubstanciar uma cultura de violência e de desigualdade entre os gêneros. Isso implica pensar em ações que superem as desigualdades entre os gêneros e as diversas manifestações da sexualidade.

É necessário que professores e professoras estejam preparados para discutir os aspectos relativos a gênero e sexualidade no espaço escolar, em um processo de enfrentamento aos cânones violentos da razão colonial, com base etnocêntrica europeia e pretensamente universalista. Enfraquecer e desestabilizar os pressupostos da visão heteronormativa que determinam uma visão binária das identidades de gênero e sexuais e que se perpetuam nos espaços sociais como modelos únicos, inalteráveis, imutáveis e "verdadeiros" deve ser objetivo de outra forma de produzir conhecimentos. Essas "verdades", segundo Foucault (1994), são disseminadas por todos os organismos sociais, constituindo-se como uma rede de interdições e de poder. Os enquadramentos dentro dos padrões estabelecidos constituem-se por relações de poder e de disciplinamento, o qual, infelizmente, ainda é parte do currículo escolar, seja prescrito, seja oculto.

O cotidiano escolar é atravessado por todo um conjunto de disciplinamentos estabelecidos sobre o que é considerado conhecimento e comportamento hegemônico, além de apontar para um cenário de fortalecimento de opressões dos corpos, 
das sexualidades, das relações étnico-raciais. A lógica vigente ainda se sustenta na binaridade do que é relativo ao feminino e do que é relativo ao masculino, desconsiderando por completo qualquer forma outra de viver a corporalidade, a sexualidade, o gênero.

As práticas de professores e professoras podem indicar formas subliminares, se não explícitas, de ocultamento das diferenças como processos socioculturais e relações de poder instalados nas salas de aula. De outro modo, tais práticas podem ser desconstruídas, à medida que não permitem que as temáticas sejam silenciadas e apagadas nos processos pedagógicos formativos.

Para Louro (2013), identidades de gênero e sexuais são demarcadas por forças sociais que se embaraçam em redes de poder. Assim, a sexualidade é uma questão política, social e cultural e é aprendida ao longo da vida, envolvendo processos profundamente plurais e culturais. Segundo a autora, as possibilidades de expressar a sexualidade, os desejos e os prazeres "também são sempre socialmente estabelecidas e codificadas. As identidades de gênero e sexuais são, portanto, compostas e definidas por relações sociais, elas são moldadas pelas redes de poder de uma sociedade" (LOURO, 2013, p. 11).

No contexto da formulação do PNE e dos Planos Estaduais e Municipais de Educação, ao ser suprimida qualquer menção a gênero e sexualidade nos documentos, transparece a intenção de se instituir a "mordaça" na prática docente, evidenciando claro ataque aos pressupostos democráticos previstos na Constituição federal quando, no inciso IV do art. $3^{\circ}$, considera a promoção: “[...] do bem estar de todos...discriminação" (BRASIL, 1988) como um dos objetivos fundamentais da República Federativa do Brasil. Além disso, afronta o art. $5^{\circ}$ que "todos são iguais perante a lei, sem distinção de qualquer natureza" (BRASIL, 1988).

O PNE e os planos de educação são documentos definidores das políticas públicas a serem implantadas e desenvolvidas pelos sistemas de educação por dez anos. Diante dessa perspectiva, há todo um conjunto de questionamentos para se pensar a partir da exequibilidade dos planos: de que forma "brincadeiras" e insultos heterossexistas e homofóbicos serão combatidos no cotidiano da escola, entendendo-os como formas perversas de discriminação? Como serão enfrentadas "todas as formas de discriminação" no ambiente escolar, incluindo as discriminações relativas a gênero e sexualidade? Que normas e disciplinamentos regem as práticas pedagógicas escolares a partir das formulações legais? De que forma as diretrizes apontadas (ou escondidas) nos planos de educação podem oferecer ferramentas para o fortalecimento de mecanismos normalizadores, ajustadores, marginalizantes e excludentes das orientações e sexualidades dissidentes? Além 
disso, que espaços há para processos de resistência e de combate ao preconceito e às práticas discriminatórias envolvendo as relações de gênero e sexualidade?

\section{Os planos de educação e as relações de gênero: aprisionar a escola no armário e amordaçar professores e professoras?}

Historicamente, o movimento gay identifica-se com a expressão "sair do armário" como o ato de publicizar a orientação sexual ou a identidade de gênero, significa que alguém, cuja orientação é homossexual, lésbica, bissexual, transgênero ou queer, não esconde sua condição. Essa capacidade de agência implica em processos complexos que envolvem aspectos psicossociais para enunciar a orientação, de romper com dispositivos de controle e de opressão da própria sexualidade, bem como pode incorrer em processos de emancipação.

De acordo com Sedgwick (2007), toda a atenção dada às questões relativas à homossexualidade, desde o final do século XX, na Europa e nos EUA, foi:

[...] impulsionada pela relação distintivamente indicativa entre homossexualidade e mapeamentos mais amplos do segredo e da revelação, do privado e do público, que eram e são criticamente problemáticos para as estruturas econômicas, sexuais e de gênero da cultura heterossexista como um todo; mapeamentos cuja incoerência capacitadora, mas perigosa, foi condensada de maneira opressiva e duradoura em certas figuras da homossexualidade. "O armário" e "a saída do armário", ou "assumir-se", agora expressões quase comuns para o potente cruzamento e recruzamento de quase todas as linhas de representação politicamente carregadas, têm sido as mais magnéticas e ameaçadoras dessas figuras (SEDGWICK, 2007, p. 26).

O "armário", metaforicamente, é um dispositivo de confinamento de todos que não seguem a orientação sexual padrão - heterossexual - e que, portanto, invisibiliza, oculta e silencia lésbicas, gays e transexuais. Dessa forma, "o armário é a estrutura definidora da opressão gay no século XX" (SEDGWICK, 2007, p. 26).

Como espaço pluriverso e diverso - em contraposição ao conceito de universo -, marca indelével da modernidade, de formação de nossas crianças, jovens e adultos, articulada com as demandas de sujeitos diversos, a escola é um dos lócus privilegiados para se construir lutas contra todo e qualquer tipo de preconceito e discriminação. Ela é o lugar da diferença. É, também, um espaço de intensa disputa.

$\mathrm{E}$ é nesse contexto de disputa que os movimentos conservadores vêm se manifestando, a partir da criação de leis que amordaçam a escola, amordaçam professores e professoras, para que não se discutam gênero e sexualidade. Esses movimentos representam setores da sociedade que buscam manter o controle sobre as vidas das pessoas e configuram-se como retrocessos quando as políticas indicadas 
no PNE e nos Planos Estaduais e Municipais de Educação em prol das diferenças e contra a discriminação, principalmente na explicitação das relações de gênero, são silenciadas, jogadas e trancadas dentro do armário, afrontando descaradamente os princípios democráticos apontados na Carta Magna de 1988.

A escola é espaço de complexas contradições presentes nas práticas sociais e as desigualdades invadem-na pelo portão de entrada. São desigualdades sociais que, apesar dos avanços consideráveis nos últimos anos, persistem em nossas cidades, principalmente, nas periferias. Ademais, essas desigualdades somam-se a outras relativas à raça, à etnia, ao gênero e à orientação sexual, configurando um quadro bastante diverso, imbrincado e nada simples, que demanda outras formas de pensar, de agir e fazer a escola.

Conforme Arroyo, "[...] os coletivos sociais, de gênero, etnia, raça, camponeses, quilombolas, trabalhadores empobrecidos que se afirmam sujeitos de direitos" (2014, p. 9) compõem-se de outros sujeitos que chegam à escola, indagam-na, problematizam-na e a desafiam. Esses outros sujeitos, principalmente se pensarmos na população LGBT, interrogam as estruturas públicas, suas interdições, suas proibições, seus dispositivos de controle bem como suas políticas. Exigem, também, seus direitos, como direito à diferença, ao nome social e ao uso de banheiro específico para transexuais.

Em conversa com uma professora de uma rede municipal do estado do Rio de Janeiro, houve o relato de uma experiência vivenciada com sua turma de educação infantil. Segundo a docente, há dois garotos de 5 anos que são amigos inseparáveis. Estão sempre juntos, abraçados e trocam "selinhos" de boca. Essa atitude vem tornando-se foco de olhares de outras professoras e da coordenadora da escola, no sentido de coibir tal comportamento, considerando como uma subversão dos padrões heteronormativos vigentes. Conforme a professora, há certo "pânico" por parte das colegas, que já "aconselharam-na" a convocar os pais e as mães das duas crianças. Essa situação indica o quão complexa tem se tornado a prática pedagógica ao percebermos que esses outros sujeitos "interrogam a docência, o pensamento pedagógico, as práticas de educação popular e escolar" (ARROYO, 2014, p. 9).

Pensar nesses outros sujeitos que adentram a escola é pensar em políticas que possam contribuir para o fortalecimento do estado democrático de direito e, principalmente, que se contraponham ao histórico espectro da exclusão. Nesse sentido, o PNE e os Planos Estaduais e Municipais de Educação configuram-se como instrumentos potentes para a inclusão, para o respeito às diferenças e para o combate à discriminação, ao preconceito e a todas as formas de violência.

A discriminação, no interior das escolas, tem como uma das principais origens a homofobia. Uma pesquisa ${ }^{6}$ realizada com estudantes do penúltimo ano do 
ensino fundamental e do último ano do ensino médio, com professores do ensino fundamental e do ensino médio, diretores, profissionais de educação, pais, mães e responsáveis por alunos, em 500 escolas de todo o país, no ano de 2009, indicou que o preconceito e a discriminação fazem parte da realidade do cotidiano escolar. Relação de gênero foi a área que apresentou o maior índice de concordância com as atitudes discriminatórias $(38,2 \%)$, seguida pelas áreas relacionadas à discriminação geracional (37,9\%), à deficiência $(32,4 \%)$, à identidade de gênero $(26,1 \%)$, a questões socioeconômicas $(25,1 \%)$, étnico-raciais $(22,9 \%)$ e territoriais $(20,6 \%)$. Observa-se, portanto, que as temáticas relacionadas a gênero comportam, conjuntamente, um alto índice de atitudes preconceituosas e discriminatórias.

Para 26,6\% dos alunos entrevistados, evidenciou-se a não aceitação da homossexualidade. Conforme $25,2 \%$, homossexuais não são confiáveis, $23,2 \%$ consideram que a homossexualidade é uma doença e 17,7\% afirmaram que alunos homossexuais deveriam estudar em salas separadas. $\mathrm{O}$ mais preocupante é que o preconceito e a discriminação, muitas vezes, provocam humilhação, agressão ou acusações injustas às pessoas por fazerem parte de algum grupo. O relatório aponta que as práticas discriminatórias na escola têm como principais vítimas os alunos negros (19\%), pobres (18\%) e homossexuais (17\%).

Castro, Abramovay e Silva (2004), coordenadoras da pesquisa Juventude e sexualidade, identificaram que 39,6\% dos meninos não gostariam de ter um colega de classe homossexual. Segundo as autoras, a homofobia é um tipo de violência na escola pouco documentado. Muitas vezes, as atitudes preconceituosas ou discriminatórias sofridas por alunos tidos como homossexuais são silenciadas. Por despreparo ou formação inadequada, professores e professoras podem colaborar ativamente na reprodução dessa violência. As ofensas, os xingamentos e as "brincadeiras" tendem a ser diminuídas, naturalizadas, prestigiadas e não entendidas como violências (CASTRO; ABRAMOVAY; SILVA, 2004).

Diante disso, a inclusão de metas e estratégias no PNE e nos Planos Estaduais e Municipais referentes a gênero e sexualidade seria de grande relevância para se garantir a constituição de uma cultura de combate ao preconceito e à discriminação na escola. No entanto, não foi o que aconteceu. Conforme já observado, a bancada religiosa e evangélica no Congresso retirou qualquer menção ao termo gênero.

O PNE encaminhado ao Congresso Nacional é fruto da I Conae $2010,{ }^{7}$ que contou com ampla participação da sociedade civil e, em especial, do segmento educacional brasileiro. Em 2013, foram realizadas as conferências municipais e/ou intermunicipais e as conferências estaduais preparatórias para a II Conae.

A II Conae 2014 somente ocorreu em novembro, após a aprovação do PNE. Dessa forma, o documento referência que serviu para subsidiar o PNE foi o Do- 
cumento Referência 2010, mas as propostas indicadas no Documento Final Conae 2014 aprimoram o conjunto de proposições feitas.

No Documento Final Conae 2010, as relações de gênero, identidade de gênero e orientação sexual foram contempladas no Eixo VI - Justiça social, educação e trabalho: inclusão, diversidade e igualdade. No documento, há uma clara defesa dos direitos de diversos sujeitos e segmentos, pensada dentro de uma perspectiva de combate às desigualdades, apontando propostas que consolidem a democracia com a garantia de justiça social, ressaltadas as questões de gênero. Logo, é responsabilidade do poder público garantir políticas que universalizem direitos para superar desigualdades. Para isso, é necessário que a diversidade seja incorporada em seus princípios, metas e estratégias. Dessa forma, “[...] o gênero, a raça, a etnia, a geração, a orientação sexual, as pessoas com deficiência, transtornos globais do desenvolvimento e altas habilidades - superdotação - são tomados como eixos e sujeitos orientadores de políticas afirmativas" (BRASIL, 2010, p. 126).

O PNE e os Planos Estaduais e Municipais devem, portanto, ser a expressão das políticas com o objetivo de garantir o direito à diversidade, consubstanciado em uma concepção de justiça social e respeito às diferenças, compreendendo que a superação das desigualdades se coloca como prioritária a partir do combate ao racismo, ao sexismo, à intolerância religiosa, à homofobia (lesbofobia, bifobia, transfobia), aos preconceitos, às discriminações e às intolerâncias diversas. Essas lutas devem ser eixos centrais das práticas pedagógicas, dos projetos político-pedagógicos e dos planos de desenvolvimento institucional de escolas públicas e privadas, em articulação com os movimentos sociais (BRASIL, 2010).

No Documento Final Conae 2010, 25 diretrizes foram apontadas para o tratamento das questões de gênero e a diversidade sexual. Dentre elas, destacam-se a indicação da necessidade de:

[...] introduzir e garantir a discussão de gênero e diversidade sexual na política de valorização e formação inicial e continuada dos/das profissionais da educação nas esferas federal, estadual, distrital e municipal, visando ao combate do preconceito e da discriminação de pessoas lésbicas, gays, bissexuais, travestis, transexuais, mulheres, ao estudo de gênero, diversidade sexual e orientação sexual, no currículo do ensino superior, levando-se em conta o Plano Nacional de Políticas Públicas para a Cidadania LGBT e o Programa Brasil sem Homofobia (BRASIL, 2010, p. 143).

Nesse sentido, explicita-se uma perspectiva de que as ações voltadas para a formação de professores devem pautar-se no combate ao preconceito e à discriminação de pessoas LGBT e de mulheres, articulando as políticas públicas educacionais ao Plano Nacional de Políticas Públicas para a Cidadania LGBT e ao Programa Brasil sem Homofobia. 
No Documento Final Conae 2014, a temática é contemplada no Eixo II: Educação e diversidade: justiça social, inclusão e direitos humanos. Logo no primeiro parágrafo do eixo, há uma clara manifestação de quais são os seus pressupostos: "Diz respeito à efetivação da educação pública democrática, popular, laica e com qualidade social, banindo o proselitismo, o racismo, o machismo, o sexismo, a homofobia, a lesbofobia e a transfobia nas instituições educativas de todos os níveis, etapas e modalidades" (BRASIL, 2014, p. 29).

O documento aponta que diversos sujeitos e grupos, historicamente, denunciam ações de violências, de violações aos direitos humanos, de desrespeito, de discriminações e intolerâncias. Ficam explícitas as violações e violências motivadas por questões de gênero, sexualidade e orientação sexual (machismo, misoginia, homofobia, bifobia, lesbofobia, transfobia). No Eixo II, há 97 proposições e estratégias indicando responsabilidades, corresponsabilidades, atribuições concorrentes, complementares e colaborativas entre os entes federados - União, Estados, Distrito Federal e municípios.

Nessas proposições, termos como diversidade sexual, gênero, orientação sexual e identidade de gênero aparecem explicitamente indicando o compromisso das políticas públicas educacionais com a superação do cenário de ódio e violência que atinge nossas escolas no trato dessas questões. Os documentos da Conae 2010 e da Conae 2014 deixam evidente que a educação no país precisa caminhar para o enfrentamento das discriminações e dos preconceitos que produzem violência, principalmente, contra as mulheres e as pessoas LGBT no cotidiano escolar.

No processo de tramitação do PNE no Congresso, diversos segmentos posicionaram-se contra qualquer menção a gênero, sexualidade ou orientação sexual no plano. Os movimentos contrários vieram de setores conservadores e religiosos. No processo de elaboração e aprovação dos Planos Municipais de Educação, a pressão desses setores ${ }^{8}$ continuou, imprimindo uma grande influência sobre as Câmaras Legislativas Estaduais e as Câmaras Municipais.

No município de Duque de Caxias, RJ, o documento referência da II Conferência Municipal de Educação de Duque de Caxias (Confeduc), realizada em 2014, estruturou as metas sob o eixo gestão democrática. Nesse eixo, foram organizados sete subeixos..$^{9}$ A temática relativa a gênero foi contemplada no subeixo III - Democratização do acesso e permanência nas diferentes modalidades e diversidades: transversalizando a educação, no subtópico Educação, gênero e saúde. O documento defende uma educação baseada nos princípios democráticos, plurais e de inclusão, comprometida com a formação para os direitos humanos e o enfrentamento de toda forma de discriminação, indicando que a estrutura curricular da rede deve privilegiar abordagens diversas e interdisciplinares baseadas na valorização da 
diversidade. Como compromisso com a diversidade, explicitam-se seus princípios norteadores para a educação no âmbito municipal:

Uma política educacional que tem por pilares a gestão compartilhada entre os diversos atores da comunidade escolar, a promoção da saúde integral e o comprometimento com uma educação inclusiva, não sexista, não racista, não lesbofóbica e não homofóbica, não somente facilita o acesso e a permanência do educando na Educação Básica, como aponta para a construção de uma sociedade mais justa, em que os direitos humanos de todas e todos sejam, de fato, respeitados (DUQUE DE CAXIAS, 2014, p. 124-125).

Há 22 proposições para que as relações de gênero sejam incluídas e discutidas nas escolas, no currículo e na formação de professores. São evidentes as referências a questões de gênero, equidade de gênero, orientação sexual, homossexualidade, transexualidade, homofobia, lesbofobia e transfobia. Destaca-se uma delas por envolver questões diretas ao combate à violência e à discriminação: "promover medidas educacionais para o enfrentamento da violência contra mulheres, considerando as dimensões étnico-raciais, geracionais e de orientação sexual, com ênfase também para o enfrentamento do abuso e exploração sexual de crianças, jovens e adolescentes" (DUQUE DE CAXIAS, 2014, p. 125).

De forma bastante comprometida com uma educação de qualidade pautada no enfrentamento das desigualdades, principalmente, relativas às questões de gênero e sexualidade, o documento aponta algumas questões a serem superadas:

A sexualidade pensada exclusivamente sob uma perspectiva biológica e heteronormativa, sem levar em conta sua dimensão cultural e histórica; a sexualidade e o exercício da mesma como forma de empoderamento nas relações de gênero; o corpo humano - sempre de pessoas brancas, tornando invisível a diversidade étnico-racial do país; o corpo humano concebido como um organismo e estudado tendo como foco principal a função reprodutiva; o estudo isolado do "aparelho reprodutor", sem considerar o papel socialmente construído para o homem e a mulher; a concepção positivista de corpo humano; a desinformação sobre a rede municipal/estadual de atendimento à mulher em situação de violência doméstica; a ideologia de que os direitos das mulheres foram "dados", dando relevância ao processo histórico que levou à conquista desses direitos; deve-se focar também na educação masculina como questão problemática, pois os homens também carregam o peso de atender às expectativas (DUQUE DE CAXIAS, 2014, p. 127).

A Lei Municipal no 2.713, de 30 de junho de 2015, que aprova a adequação do Plano Municipal de Educação de Duque de Caxias ao PNE para o decênio 20152015, em seu art. $2^{\circ}$, inciso III, mantém o texto do PNE: superação das desigualdades educacionais, com ênfase na promoção da cidadania e na erradicação de todas as formas de discriminação. Infelizmente, todo o tópico "Educação, gênero e saúde", definido na II Confeduc, foi suprimido da lei.

Já o processo de construção do Documento Base do Plano Municipal de Educação da cidade de Nova Iguaçu 2015-2025 foi iniciado por meio da Portaria Semed 
no 074/2014, com a constituição da Equipe Técnica de Adequação (ETA) do PME. A ETA elaborou a análise situacional do município adequando o PME (2008-2018). $\mathrm{O}$ documento seguiu para as escolas com a finalidade de fomentar discussões das metas e estratégias estabelecidas para o PME 2015-2025.

O documento apresenta 20 metas, em conformidade com o PNE. Em todo o documento, não foi encontrada qualquer menção aos termos gênero, sexualidade, orientação sexual, etc. $\mathrm{O}$ documento, bastante técnico, desconsidera qualquer relação com os pressupostos de educação de qualidade social que sejam pautados nos princípios do respeito à diferença, à diversidade. Há apenas algumas referências bastante genéricas enfocando estratégias de possível enfrentamento a todas as formas de violência e de discriminação. Na estratégia 2.4 , da meta 2 , que prevê a universalização do ensino fundamental de 9 anos para toda a população de 6 (seis) a 14 (quatorze) anos e garantia de que pelo menos $80 \%$ dos alunos concluam essa etapa na idade recomendada, há uma estratégia que faz alusão às situações de discriminação, preconceito e violência na escola.

[...] fortalecer o acompanhamento e o monitoramento do acesso, da permanência e do aproveitamento escolar dos beneficiários de Programa Bolsa Família, bem como das situações de discriminação, preconceitos e violências na escola, visando ao estabelecimento de condições adequadas para o sucesso escolar [...] (NOVA IGUAÇU, 2015, p. 23).

Na meta 3 - Universalizar o atendimento escolar para toda a população de 15 a 17 anos, ampliar a oferta de cursos técnicos e elevar a taxa líquida de matrículas no ensino médio para 85\% -, as estratégias 3.12 e 3.21 também fazem referência ao combate à discriminação e ao preconceito de forma muito inespecífica:

[...] promover ações de combate e prevenção às situações de discriminação, preconceitos e violências, práticas irregulares de exploração do trabalho, consumo de drogas, gravidez precoce, em colaboração com as famílias e com órgãos públicos de assistência social, saúde e proteção à adolescência e juventude.

[...] implementar políticas de prevenção à evasão motivada por preconceito ou quaisquer formas de discriminação, criando rede de proteção contra formas associadas de exclusão (NOVA IGUAÇU, 2015, p. 32, 34).

A Lei Municipal no 4.504, de 23 de junho de 2015, que dispõe sobre o Plano Municipal de Nova Iguaçu para o decênio 2015-2025, foi aprovada sem qualquer referência às relações de gênero, seguindo o mesmo teor do Documento Base. Em uma direção inconstitucional e repressora, foi aprovada na Câmara Municipal da cidade a Lei $\mathrm{n}^{\circ}$ 4.576, de 15 de fevereiro de 2016, que veda a distribuição, exposição e divulgação de material didático contendo orientações sobre diversidade sexual nos estabelecimentos de ensino da rede pública do município, o que inclui a proibição de qualquer ação que vise ao combate da homofobia. 
O estado do Rio de Janeiro é pioneiro na ampliação de direitos da comunidade LGBT e, desde 2007, implementa políticas em defesa dos direitos dessa população. O Programa Rio sem Homofobia visa combater a discriminação e a violência contra a comunidade LGBT e promover a sua cidadania no estado. A publicação da referida lei mobilizou o movimento LGBT local, professores e professoras do município bem como representantes do Programa Rio sem Homofobia e do Ministério Público do Estado do Rio de Janeiro (MPRJ) para discutir com o prefeito os problemas que envolvem a implantação de tal lei.

É importante defendermos a escola como um espaço público, democrático e plural. Portanto, qualquer tipo de imposição que desrespeite os direitos da população, em uma sociedade democrática, é, no mínimo, a expressão máxima de autoritarismo. Além disso, a lei municipal fere o artigo $5^{\circ}$ da Constituição federal, que determina que: "[...] todos são iguais perante a lei, sem distinção de qualquer natureza, garantindo-se aos brasileiros e aos estrangeiros residentes no país a inviolabilidade do direito à vida, à liberdade, à igualdade, à segurança e à propriedade" (BRASIL, 1988).

\section{Considerações em processo: espaços de enfrentamento das práticas discriminatórias}

A escola não só reproduz desigualdades e distinções, mas também as produz. Assim, podemos problematizar as formas pelas quais as relações de gênero se estabelecem e como as questões relativas à diversidade e à orientação sexual se constituem nesse espaço. Essa formulação escolar é herança da sociedade ocidental moderna, como discutimos na seção anterior, e tem produzido, historicamente, preconceitos, estereótipos e sujeitos estigmatizados. A escola foi pensada, inicialmente, para acolher apenas alguns, não todos. Depois, aos poucos, foi sendo demandada por outros sujeitos, que trouxeram transformações importantes, por isso, ela "precisou ser diversa: organização, currículos, prédios, docentes, regulamentos, avaliações iriam, explícita ou implicitamente, 'garantir' - e também produzir - as diferenças entre os sujeitos” (LOURO, 2014, p. 61).

O desafio da escola, na contemporaneidade, concentra-se no acolhimento e trato adequado das diferenças. Não se trata apenas de "aceitar" os diferentes, mas de construir uma cultura de respeito ao outro que age diferente, que pensa diferente, que se relaciona diferente.

No conjunto do PNE e dos Planos Municipais de Educação, as disputas impetradas, principalmente, por setores conservadores e religiosos, conseguiram relativa "vitória" sobre o apagamento e silenciamento das relações de gênero nas práticas escolares. As relações de gênero e a diversidade sexual tornam-se temas 
fulcrais na contemporaneidade, devido à complexidade e à multiplicidade de comportamentos, valores e culturas, além de ser parte constituinte de identidades. Professores e professoras, ao contrário do que pensam alguns movimentos conservadores, devem enfrentar tal desafio, formando-se e inserindo a discussão em suas aulas, em suas práticas. Não devem deixar que a "mordaça" seja instrumento para calar suas vozes e suas lutas em prol de uma educação inclusiva e verdadeiramente democrática.

A escola é um dos espaços potentes para incorporar e abarcar essa discussão. Miskolci (2014) considera que a escola e as práticas nela realizadas podem "quebrar o silêncio" sobre relações de gênero e sexualidade. Professores e professoras podem abordar aspectos inerentes à sexualidade e questões de gênero a partir de situações do cotidiano, de assuntos expostos na mídia, da discussão de um filme ou da leitura de um romance, de uma matéria jornalística, de uma campanha publicitária. Para o autor, as práticas pedagógicas que tratam da diversidade sexual podem ser potentes para coibir preconceitos e discriminações. Caso um menino ou uma menina rompa com uma convenção de gênero e sofra xingamentos e humilhações dos colegas, o professor ou a professora deve se manifestar de forma a restabelecer o respeito a quem foi 'insultado'. Tal atitude contribuirá para que todos se confrontem com uma forma diferente de agir e pensar.

A Secretaria de Educação Continuada, Alfabetização, Diversidade e Inclusão (Secadi) divulgou, por meio da Nota Técnica no 24/2015, que o Ministério da Educação reitera a importância da inserção dos conceitos de gênero e orientação sexual para as políticas públicas em educação, visando à construção de uma escola efetivamente democrática, que focalize o respeito às diferenças e enfrente as desigualdades e violências. Além disso, as concepções de gênero e de orientação sexual ajudam a entender as desigualdades históricas entre homens e mulheres, além de contribuírem para diferentes formas de discriminação e violência.

O CNE (Conselho Nacional de Educação) também se pronunciou e emitiu nota pública endereçada às Assembleias Legislativas, à Câmara Legislativa do Distrito Federal, às Câmaras de Vereadores, aos Conselhos Estaduais, Distrital e Municipais de Educação e à Sociedade Brasileira, em que manifesta surpresa e preocupação acerca da omissão de questões relativas à diversidade cultural e de gênero:

O CNE manifesta sua surpresa - pelas normas e orientações em vigor - e preocupação com planos de educação que vem sendo elaborados por entes federativos brasileiros e que têm omitido, deliberadamente, fundamentos, metodologias e procedimentos em relação ao trato das questões relativas à diversidade cultural e de gênero, já devidamente consagrados no corpus normativo do País para a construção da cidadania de segmentos específicos da população brasileira e sobre o qual não pode permanecer qualquer dúvida quanto à propriedade de seu tratamento no campo da educação (BRASIL, 2015, p. 2). 
O CNE avalia que os planos de educação encontram-se incompletos e devem ser revisados por conta da ausência ou insuficiência do foco nas temáticas relativas à diversidade de gênero. Essa orientação para que se faça uma revisão nos planos pode ser importante para tirar a escola do armário. Conforme Rios (2014), é possível constituir respostas jurídicas de enfrentamento do preconceito, da discriminação e da violência contra sujeitos que não se encaixam nas sexualidades hegemônicas. Por meio de políticas, diretrizes e estratégias de respeito à diversidade sexual, é possível promover mudanças no sentido de superação de preconceitos e discriminações consolidadas. Nesse sentido, o PNE e os planos de educação podem servir como instrumentos fundamentais para tal enfrentamento. Rios afirma que:

[...] a intolerância viola o direito à existência simultânea das diversas identidades e expressões da sexualidade, que é um bem comum indivisível. Uma vez acionada, a intolerância ofende o pluralismo, que é requisito para uma vida democrática. Daí a compreensão de que os chamados crimes de ódio, manifestação que merece intensa reprovação jurídica, atentam contra a convivência democrática. Daí também a propriedade de utilização de ações coletivas para a proteção e promoção do direito ao reconhecimento das identidades forjadas e estigmatizadas num contexto heterossexista (RIOS, 2014, p. 262-263).

Tais documentos podem contribuir para o movimento de resistência aos apagamentos e silenciamentos que se materializaram no PNE, nos Planos Estaduais e Municipais de Educação. Seguindo sobre a legislação vigente para o combate a discriminações e preconceitos diversos, em 2015, foi sancionada a Lei oㅜ 13.185 , que institui o Programa de Combate à Intimidação Sistemática (bullying) e que pode servir como suporte para o trabalho de docentes, no interior da escola, resguardando-os de qualquer tipo de intervenção ou intimidação por parte de leis locais. A lei caracteriza, de forma bastante específica, as situações diversas que envolvem agressão física, psicológica e moral. Além disso, estabelece regras para definir casos de intimidação realizados pela internet. O programa tem como finalidade a prevenção e o combate das práticas sistemáticas de intimidação em todo o país. Todo e qualquer ato de violência física ou psicológica, intencional e repetitivo, produzido sem motivação evidente e por indivíduo ou grupo, contra uma ou mais pessoas, com o objetivo de intimidá-la ou agredi-la, provocando dor e angústia às vítimas, será considerado intimidação sistemática - bullying.

No $\S 2^{\circ}$ do art. $1^{\circ}$, a lei indica que o programa servirá para fundamentar as ações do Ministério da Educação e das Secretarias Estaduais e Municipais de Educação. A violência física ou psicológica em atos de intimidação, humilhação ou discriminação, como ataques físicos, insultos pessoais, comentários sistemáticos e apelidos pejorativos, ameaças por quaisquer meios, grafites depreciativos, expressões preconceituosas, isolamento social consciente e premeditado e pilhérias, caracteriza a intimidação sistemática. 
A lei também indica que o cyberbullying - intimidação na internet -, com o uso de instrumentos que lhe são próprios para depreciar, incitar a violência, adulterar fotos e dados pessoais com o intuito de criar meios de constrangimento psicossocial, também caracteriza o teor da intimidação sistemática.

No art. $3^{\circ}$, a lei considera que ações praticadas verbalmente (insultar, xingar e apelidar pejorativamente), moralmente (difamar, caluniar, disseminar rumores), sexualmente (assediar, induzir e/ou abusar), socialmente (ignorar, isolar e excluir), psicologicamente (perseguir, amedrontar, aterrorizar, dominar, manipular, chantagear e infernizar), fisicamente (socar, chutar, bater), materialmente (furtar, roubar, destruir pertences de outrem) e virtualmente (depreciar, enviar mensagens intrusivas da intimidade, enviar ou adulterar fotos e dados pessoais que resultem em sofrimento ou com o intuito de criar meios de constrangimento psicológico e social) são formas de materialização/caracterização do bullying.

O referido programa indica como proposições a formação de docentes e equipes pedagógicas para implementação de ações de discussão, prevenção, orientação e solução de problemas; de implementação e disseminação de campanhas educativas para conscientização e informação; de instituição de práticas de conduta e orientação de pais, familiares e responsáveis da identificação de vítimas e agressores; de assistir psicológica, social e juridicamente às vítimas e aos agressores.

A relevância dessa lei está na possibilidade de combater toda e qualquer forma de preconceito e discriminação no ambiente escolar. A lei estabelece que é dever dos estabelecimentos de ensino, dos clubes e das agremiações recreativas assegurar medidas de conscientização, prevenção, diagnose e combate à violência e à intimidação sistemática - bullying. No caso da Lei no 4.576/2016, sancionada pelo prefeito de Nova Iguaçu, o MPRJ, por meio da Promotoria de Justiça e Tutela Coletiva de Proteção à Educação - Núcleo Nova Iguaçu -, abriu inquérito (Inquérito Civil $n^{0}$ 300/2016) para apurar as incongruências e inconsistências da lei. Além disso, encaminhou a Recomendação n⿳ 02/2016 à Prefeitura de Nova Iguaçu para que "o chefe do poder executivo municipal determine aos seus subordinados que deixem de aplicar a lei municipal manifestamente inconstitucional e implante política de combate à intimidação sistemática (bullying) e respeito a diversidades nas escolas municipais" (MPRJ, 2016, p. 1).

De acordo com Colling e Nogueira (2014), além do apoio legal, há algumas alternativas para combater as violências que envolvem questões de gênero e de orientação sexual: denunciar e dar visibilidade às violações sofridas por sujeitos que são dissidentes da norma heterossexual; revelar o caráter histórico e construído das sexualidades; evidenciar que a norma hegemônica heterossexual produz homofobia, lesbofobia, bifobia, transfobia e outros preconceitos contra formas outras de vivenciar heterossexualidades e possibilidade de aglutinar coletivos de pessoas de diferentes categorias para o enfrentamento da produção de subalternidades. 
Nesse sentido, é essencial intensificar a discussão e a problematização sobre a temática da diversidade e da orientação sexual, bem como visibilizar as relações de gênero. Além disso, é preciso enfrentar a discriminação, o preconceito, o sexismo, a homofobia e toda e qualquer forma de opressão e violência aos que se colocam como diferentes e fora dos enquadres hegemônicos. A escola é um dos espaços primordiais para tal intento.

\section{Notas}

1 O projeto de lei do Executivo, enviado em dezembro de 2010, previa a aprovação do PNE para o decênio 2011-2020. Depois de concluída a tramitação, o texto final precisou fazer a adequação, estabelecendo o PNE 2014-2024. Dessa forma, ao fazermos qualquer referência ao projeto encaminhado pelo Executivo, manteremos a data do documento oficial, 2011-2010, quando for à Lei $\mathrm{n}^{\circ}$ 13.005/2014, a referência será 2014-2024.

2 A Conae é um espaço democrático que propõe articulação do poder público com a sociedade para participar das decisões sobre o desenvolvimento da educação em âmbito nacional. A I Conae aconteceu no período de 28 de março a $1^{\circ}$ de abril de 2010, em Brasília, para subsidiar a elaboração do PNE 2011-2021. A II Conae, realizada no período de 19 a 23 de novembro de 2014, também em Brasília, cujo tema foi "O PNE na articulação do Sistema Nacional de Educação: participação popular, cooperação federativa e regime de colaboração", foi convocada pela Portaria no 1.410, de 3 de dezembro de 2012, com caráter deliberativo, para apresentar propostas como subsídios para a implementação do PNE, definindo responsabilidades, corresponsabilidades, atribuições concorrentes, complementares e colaborativas entre os entes federados e os sistemas de ensino (BRASIL, 2014).

3 A Baixada Fluminense é composta por treze municípios localizados na Região Metropolitana do Rio de Janeiro.

4 De maneira geral, a expressão designa, no meio gay, o ato de assumir sua orientação sexual e sua identidade de gênero. Encontrar-se escondido, silenciado, apagado, invisível representa "estar no armário".

5 Seguindo a onda conservadora no país, estados e municípios movimentam-se no sentido de afrontar direitos. Em 2016, alguns criaram leis apelidadas de "Leis da Mordaça", por conterem conteúdo extremamente antidemocrático. Em fevereiro, Nova Iguaçu, no estado do Rio de Janeiro, aprovou lei que veda a divulgação, distribuição e circulação de qualquer material que trate da diversidade sexual e de gênero nas escolas municipais. No município de Campo Grande, estado do Mato Grosso do Sul, em março, a Câmara de Vereadores aprovou lei que proíbe qualquer discussão sobre religião, política ou sexualidade. Em abril, a Assembleia Legislativa de Alagoas, um dos estados mais pobres, com um dos mais altos índices de analfabetismo e com um dos piores índices de desenvolvimento humano, aprovou uma lei que joga mais ainda o estado no atraso. Deputados estaduais aprovaram lei que prevê punição aos professores que emitirem opiniões sobre questões políticas, religiosas ou de gênero e sexualidade em suas aulas. Segundo a lei, fica proibida a doutrinação política e ideológica em sala de aula bem como induzir nos alunos um único pensamento religioso, político ou ideológico.

6 Relatório Analítico Final - Projeto de estudo sobre ações discriminatórias no âmbito escolar, organizadas de acordo com áreas temáticas, a saber: étnico-racial, gênero, geracional, territorial, necessidades especiais, socioeconômica e orientação sexual (MEC, INEP, FIPE, USP - 2009).

7 No primeiro semestre de 2009, a partir de um Documento Referência, foram realizadas as conferências municipais e/ou intermunicipais. No segundo semestre daquele ano, ocorreram as conferências estaduais. De 28 de março a $1^{\circ}$ de abril de 2010, ocorreu a I Conae.

8 A Confederação Nacional dos Bispos do Brasil emitiu uma nota, em junho de 2015, alertando para as tentativas de incorporar a "ideologia de gênero" nos Planos Estaduais e Municipais. O argumento principal insere-se na contrariedade ao PNE, que foi aprovado sem os termos. Além disso, alega-se que esse não é o caminho para combater a discriminação pela orientação sexual. Contraditoriamente, a nota informa também que a igreja católica se compromete com o combate a todo tipo de discriminação.

9 I - Instrumentos e mecanismos da gestão democrática; II - Democratização do acesso e permanência; III Democratização do acesso e permanência nas diferentes modalidades e diversidades: transversalizando a educação; IV - Formação e valorização dos profissionais da educação, formação continuada e em serviço; V - Estrutura, financiamento, funcionamento e controle social da educação; VI - Avaliação e acompanhamento; VII - Emendas aditivas. 


\section{Referências}

ARROYO, M. G. Outros sujeitos, outras pedagogias. 2. ed. Petrópolis, RJ: Vozes, 2014.

BRASIL. Constituição da República Federativa do Brasil de 1988. Brasília, DF, 1988. Disponível em: <http://www.planalto.gov.br/ccivil_03/constituicao/ConstituicaoCompilado.htm>. Acesso em: 25 mar. 2016.

. Emenda Constitucional no 59, de 11 de novembro de 2009. Brasília, DF, 2009. Disponível em: <http://www.planalto.gov.br/ccivil_03/constituicao/emendas/emc/emc59.htm>. Acesso em: 25 mar. 2016.

Ministério da Educação. Conselho Nacional de Educação. Nota pública. Brasília, 2015. Disponível em: <http://www.deolhonosplanos.org.br/wp-content/uploads/2015/09/Nota-P\%C3\%BAblica-do-CNE-Identidade-de-G\%C3\%AAnero-9-2015.pdf>. Acesso em: 25 mar. 2016.

Ministério da Educação. Documento final: I Conae. Brasília, 2010. Disponível em: $<$ http://conae.mec.gov.br/images/stories/pdf/pdf/documetos/documento_final_sl.pdf $>$. Acesso em: 25 mar. 2016.

Ministério da Educação. Documento final: II Conae. Brasília, 2014. Disponível em: <http://fne.mec.gov.br/images/doc/DocumentoFina240415.pdf>. Acesso em: 25 mar. 2016.

. Ministério da Educação. Nota técnica no 24/2015. Brasília, 2015. Disponível em: <http:// www.spm.gov.br/assuntos/conselho/nota-tecnica-no-24-conceito-genero-no-pne-mec.pdf>. Acesso em: 25 mar. 2016.

Ministério da Educação. Plano Nacional de Educação 2014-2024. Disponível em: <http://www.observatoriodopne.org.br/uploads/reference/file/439/documento-referencia.pdf $>$. Acesso em: 25 mar. 2016.

CASTRO, M. G.; ABRAMOVAY, M.; SILVA, L. B. (Org.). Juventude e sexualidade. Brasília: Unesco Brasil, 2004.

COLLING, Leandro; NOGUEIRA, Gilmaro. Relacionados mas diferentes: sobre os conceitos de homofobia, heterossexualidade compulsória e heteronormatividade. In: RODRIGUES, Alexsandro; DALLAPÍCULA, Catarina; FERREIRA, Sérgio R. da S. (Org.). Transposições: lugares e fronteiras em sexualidade e educação. Vitória: Edufes, 2014. p. 171-183.

DUQUE DE CAXIAS. Lei nº 2713/2015. Plano Municipal de Educação de Duque de Caxias. Duque de Caxias, RJ, 2015.

. Plano Municipal de Duque de Caxias: II Confeduc. Duque de Caxias, RJ, 2014.

FOUCAULT, M. História da sexualidade I: vontade de saber. Trad. Pedro Tamen. Lisboa: Relógio D’Água Editores, 1994.

JUNQUEIRA, R. D. A pedagogia do armário: heterossexismo e vigilância de gênero no cotidiano escolar. Revista Educação On-line, Rio de Janeiro, n. 10, p. 64-83, 2012. Disponível em: <http:// www.maxwell.lambda.ele.pucrio.br/rev_edu_online.php?strSecao=input0>. Acesso em: 25 mar. 2016. 
. Heteronormatividade e vigilância de gênero no cotidiano escolar. In: RODRIGUES, Alexsandro; DALLAPÍCULA, Catarina; FERREIRA, Sérgio R. da S. (Org.). Transposições: lugares e fronteiras em sexualidade e educação. Vitória: Edufes, 2014. p. 101-124.

LOURO, G. L. Gênero, sexualidade e educação: uma perspectiva pós-estruturalista. 16. ed. Petrópolis, RJ: Vozes, 2014.

O corpo educado: pedagogias da sexualidade. 3. ed. Belo Horizonte: Autêntica, 2013.

RIO DE JANEIRO. Ministério Público do Estado do Rio de Janeiro. Recomendação no 02/2016. Nova Iguaçu, 2016. Disponível em: <http://www.mprj.mp.br/documents/112957/2081698/insconst_lei_municipal.pdf>. Acesso em: 26 maio 2016.

MISKOLCI, R. Sexualidade e orientação sexual. In: sino escolar. São Carlos: EdUFSCar, 2014. (Org.). Marcas da diferença no en. Teoria queer: um aprendizado pelas diferenças. 2. ed. Belo Horizonte: Autêntica, 2012.

NOVA IGUAÇU. Plano Municipal de Educação da Cidade de Nova Iguaçu 2015-2025. Nova Iguaçu, RJ, 2015.

RIOS, R. R. O conceito de homofobia na perspectiva dos direitos humanos e no contexto dos estudos sobre preconceito e discriminação. In: RODRIGUES, Alexsandro; DALLAPÍCULA, Catarina; FERREIRA, Sérgio R. da S. (Org.). Transposições: lugares e fronteiras em sexualidade e educação. Vitória: Edufes, 2014. p. 229-267.

SEDGWICK, E. K. A epistemologia do armário. Cadernos Pagu, Campinas, n. 28, p. 19-54, jan./ jun. 2007. Disponível em: <http://www.scielo.br/pdf/cpa/n28/03.pdf>. Acesso em: 25 mar. 2016. 